University of Nebraska - Lincoln

DigitalCommons@University of Nebraska - Lincoln

\title{
Factors associated with screening or treatment initiation among male United States veterans at risk for osteoporosis fracture
}

\author{
Richard E. Nelson \\ George E. Wahlen Department of Veterans Affairs Medical Center \\ Jonathan R. Nebeker \\ University of Utah Department of Internal Medicine \\ Brian C. Sauer \\ University of Utah Department of Internal Medicine \\ Joanne LaFleur \\ University of Utah Department of Pharmacotherapy
}

Follow this and additional works at: https://digitalcommons.unl.edu/publichealthresources

Part of the Public Health Commons

Nelson, Richard E.; Nebeker, Jonathan R.; Sauer, Brian C.; and LaFleur, Joanne, "Factors associated with screening or treatment initiation among male United States veterans at risk for osteoporosis fracture" (2012). Public Health Resources. 188.

https://digitalcommons.unl.edu/publichealthresources/188

This Article is brought to you for free and open access by the Public Health Resources at DigitalCommons@University of Nebraska - Lincoln. It has been accepted for inclusion in Public Health Resources by an authorized administrator of DigitalCommons@University of Nebraska - Lincoln. 


\title{
Factors associated with screening or treatment initiation among male United States veterans at risk for osteoporosis fracture
}

\author{
Richard E. Nelson ${ }^{\text {a,b,* }}$, Jonathan R. Nebeker ${ }^{\text {a,b }}$, Brian C. Sauer ${ }^{\text {a,b }}$, Joanne LaFleur ${ }^{\text {a,c }}$ \\ a George E. Wahlen Department of Veterans Affairs Medical Center, Salt Lake City, UT, USA \\ ${ }^{\mathrm{b}}$ University of Utah Department of Internal Medicine, Salt Lake City, UT, USA \\ c University of Utah Department of Pharmacotherapy, Salt Lake City, UT, USA
}

\section{A R T I C L E I N F O}

\section{Article history:}

Received 15 July 2011

Revised 4 November 2011

Accepted 21 November 2011

Available online 18 January 2012

Edited by: Robert Recker

\section{Keywords:}

Osteoporosis

Bisphosphonate

BMD

Veterans

Prognostic modeling

\begin{abstract}
A B S T R A C T
Male osteoporosis continues to be under-recognized and undertreated in men. An understanding of which factors cue clinicians about osteoporosis risk in men, and which do not, is needed to identify areas for improvement. This study sought to measure the association of a provider's recognition of osteoporosis with patient information constructs that are available at the time of each encounter. Using clinical and administrative data from the Veterans Health Administration system, we used a stepwise procedure to construct prognostic models for a combined outcome of osteoporosis diagnosis, treatment, or a bone mineral density (BMD) test order using time-varying covariates and Cox regression. We ran separate models for patients with at least one primary care visit and patients with only secondary care visits in the pre-index period. Some of the strongest predictors of clinical osteoporosis identification were history of gonadotropin-releasing hormone $(\mathrm{GnRH})$ agonist exposure, fragility fractures, and diagnosis of rheumatoid arthritis. Other characteristics associated with a higher likelihood of having osteoporosis risk recognized were underweight or normal body mass index, cancer, fall history, and thyroid disease. Medication exposures associated with osteoporosis risk recognition included opioids, glucocorticoids, and antidepressants. Several known clinical risk factors for fracture were not correlated with osteoporosis risk including smoking and alcohol abuse. Results suggest that clinicians are relying on some, but not all, clinical risk factors when assessing osteoporosis risk.
\end{abstract}

(c) 2011 Elsevier Inc. All rights reserved.

\section{Introduction}

As the median age of the US population increases, hip fracture rates are expected to double by the year 2040 [1]. The direct medical cost of osteoporotic fractures in the United States (US) was $\$ 17$ billion in 2005 [2]. Because of the substantial clinical and economic burden associated with osteoporotic fractures, the National Osteoporosis Foundation (NOF) and International Society for Clinical Densitometry (ISCD) have recommended bone mineral density (BMD) testing for men over the age of $70[3,4]$.

Reports continue to show that osteoporosis is even more drastically under-diagnosed and under-treated in men than in women [5-9]. In a cohort of managed care patients, only $7 \%$ of men with a prior fragility fracture received osteoporosis-specific medication [7], compared to $20-24 \%$ of women $[6,8]$. One hospital-based study showed that the rate of post-fracture treatment in men was half that of women with the same risk factors [9]. In addition, when men do break a bone, they experience worse outcomes. Hip fractures are twice as deadly for men

\footnotetext{
* Corresponding author at: University of Utah Department of Internal Medicine, Salt Lake City, UT, USA.

E-mail address: richard.nelson@utah.edu (R.E. Nelson).
}

compared to women [10], and physical functioning also deteriorates more for men following hip fractures [11].

The reasons for this under-treatment and its consequences are not well understood. Several published studies have evaluated the osteoporosis clinical decision-making processes - including predictors of treatment, diagnosis, and BMD testing - in both sexes [12-15], and one study has looked exclusively at males [7]. Unfortunately, taken together, these studies are limited in their applicability to US men. For instance, one study evaluated a non-US population, and so does not reflect patterns of care in the US [12]. Most other studies failed to evaluate predictors separately for men and women [13-15]. This is essential because, as Vanasse and colleagues showed in a cohort of Quebecois, predictors of treatment and BMD testing differ substantially between men and women [12]. Some studies were based on patient surveys rather than data from clinical encounters [13,15], which would exclude data observable to clinicians as potential cues. One of the studies focused only on treatment decisions post-fracture and so failed to provide useful information about interventions intended to prevent the first fracture [7]. Finally, none of the prior analyses modeled the predictors so as to allow patient characteristics to vary over time. This is important because characteristics that develop in close temporal proximity to a treatment or screening decision are more likely to be cues for that decision. 
Our goal in this study was to improve upon the work done by others [7,12-15] and identify characteristics that cue clinicians to identify osteoporosis or osteoporosis risk among men. To that end, we modeled potential predictors of diagnosis, treatment, or BMD testing using a male US veteran population. We used time-varying Cox proportional hazards modeling with time-varying covariates to enhance discrimination of factors that were temporally associated with clinical identification, as well as information constructs that were observable to clinicians in the patient care record at the time of each encounter. Finally, because recognition of osteoporosis may vary by the type of provider, we stratified our analysis based on wether patients were seen for primary care or specialty care needs.

\section{Methods}

\section{Study design and patients}

We used a historical cohort design to evaluate the association between observable clinical characteristics and outcomes related to clinically identified osteoporosis or fracture risk. Our primary endpoint was a composite outcome we termed "clinical identification of osteoporosis or fracture risk," defined as the first documentation of an event that indicates the clinician was aware of osteoporosis risk.

We identified male veterans who received care in the Veterans Health Administration (VHA) system in the Rocky Mountain region of the US (Veterans Integrated Service Network [VISN] 19) in 2005-2006 and who were $\geq 70$ years by January 1,2005 . This age cutoff was chosen due to the NOF's and ISCD's recommendation of BMD testing for all men age 70. We excluded patients without a prior encounter in the VHA system at least 395 days before their index encounter (the first encounter in 2005-2006) in order to ensure an adequate period of observation for assessing baseline characteristics. We also excluded patients who had the composite outcome of interest as of the index date (an osteoporosis diagnosis, an osteoporosis treatment, or a BMD test order). Patients with missing body mass index (BMI) information were excluded in an iterative manner. We originally intended to include these patients, but upon discovering that BMI was an important variable in predicting clinical identification of osteoporosis or fracture risk, we ultimately decided to exclude them. Administrative data from 2002 through 2007 were obtained including diagnoses and procedures from the VHA National Medical SAS datasets and vital signs and pharmacy data from the VHA local data warehouse. Patients were censored at the first occurrence of an outcome or on December 31, 2007, whichever occurred first. Finally, patients were considered primary care patients if they had at least one primary care visit in the VHA prior to the index date. Patients without a primary care visit were considered specialty care patients.

\section{Outcome}

The outcome of interest in this study was the first occurrence after the index date of an event suggesting clinical identification of osteoporosis or osteoporosis risk. This was defined as either (1) a diagnosis of osteoporosis, indicated by diagnosis codes $733^{* *}$; (2) a prescription order for calcitonin, parathyroid hormone, or an osteoporosis bisphosphonate (i.e., alendronate, ibandronate, or risedronate; zoledronic acid was not yet marketed during the study period) dispensed from the outpatient pharmacy; or (3) an order for a BMD test, indicated by current procedural terminology (CPT) codes for dual-energy X-ray absorptiometry, quantitative computed tomography, qualitative ultrasound, single and dual photon absorptiometry, digital X-ray radiogrammetry, and single energy X-ray absorptiometry.

\section{Independent variables}

Predictors of osteoporosis recognition that we considered included variables with a known or theoretical association with bone health or fall risk (e.g., age, BMI, race), comorbid conditions, drug exposures, and the number of inpatient and outpatient visits in the year prior to the index date (a surrogate marker for system familiarity with the patient). Each predictor variable was characterized at baseline, as far back as January 1, 2002. Each predictor variable was also allowed to change each quarter during follow-up period, with patients contributing person-time to different levels for each covariate as the patients' clinical characteristics changed over time.

\section{Statistical analysis}

Descriptive statistics were used to characterize the baseline demographic and clinical characteristics of our cohort. We then performed a series of univariate Cox proportional hazards regressions with timevarying covariates to determine if predictors were significantly associated with clinical identification of osteoporosis. Risk factors that were significant in univariate analyses at an a priori alpha level of 0.2 were considered candidate risk factors. We then performed a multivariable stepwise selection procedure, in which candidate risk factors were introduced one at a time and those with $p$-values $>0.10$ were excluded. A stepwise selection procedure was used because of the predictive nature of our research question. Because the candidate variables in our model are pre-specified, i.e. identified based on association with bone health or fall risk from previous studies, a multiplicity adjustment is not warranted here [16]. All statistical tests were performed using SAS v. 9.2.

\section{Results}

Patients

Of the 48,183 males who met the inclusion criteria, we excluded $2452(2.3 \%)$ who had the outcome of interest on or before baseline and 11,449 (23.2\%) with missing or invalid BMI data. This resulted in a cohort of 34,282 patients, 9037 of whom were primary care patients and 25,245 of whom were specialty care patients. Descriptive characteristics of the patients at baseline are summarized in Table 1. The two groups of patients were similar in terms of race (91.2\% of primary care patients and $91.8 \%$ of specialty care patients were white) while primary care patients ( $40.8 \%$ age 80 or older) were older than specialty care patients ( $31.4 \%$ age 80 or older). The most common diseases as of baseline for both groups of patients were hypertension (85.4\% for primary care patients; $79.1 \%$ for specialty care patients), diabetes ( $54.3 \%$ for primary care patients; $46.7 \%$ for specialty care patients), and cancer (32.8\% for primary care patients; $20.3 \%$ for specialty care patients). Statins were the most common medication for which previous exposure was captured for both primary care (56.8\%) and secondary care patients (55.8\%). Nearly half of the primary care patients had been exposed to opioids at baseline $(47.8 \%$ ) and roughly one-third had a history of exposure to thiazide diuretics (34.6\%) and $\mathrm{H}-2$ receptor antagonists (30.1\%) at baseline. Similarly, exposure to thiazide diuretics (29.4\%) and $\mathrm{H}-2$ receptor antagonists (19.1\%) was common among specialty care patients.

Both the primary and specialty care patients had an average followup time of 2.8 years. During this follow-up time 467 (5.2\%) of the 9037 primary care patients and $782(3.1 \%)$ of the 25,245 specialty care patients had the composite endpoint. This corresponds to an incidence of 18.3 events and 11.3 events per 1000 person-years, respectively. Among those who had the outcome, the average time to clinical identification of osteoporosis or fracture risk was 1.4 years for both groups of patients.

Clinical identification of osteoporosis or osteoporosis risk in primary care patients

The predictive model results are summarized in Table 2 . In the multivariable model for primary care patients, neither race nor age was a significant predictor of clinical identification of osteoporosis. 
Table 1

Frequency of risk factors of clinical identification of osteoporosis or fracture risk ${ }^{\mathrm{a}}$ at baseline and number of patients identified with each risk factor.

\begin{tabular}{|c|c|c|c|c|c|c|c|c|}
\hline \multirow[b]{3}{*}{ Characteristic } & \multicolumn{4}{|c|}{ Primary Care Visit $(\mathrm{N}=9037)$} & \multicolumn{4}{|c|}{ Specialty Care Visits Only $(\mathrm{N}=25,245)$} \\
\hline & \multicolumn{2}{|c|}{ Frequency at Baseline } & \multicolumn{2}{|c|}{ Number with Events } & \multicolumn{2}{|c|}{ Frequency at Baseline } & \multicolumn{2}{|c|}{ Number with Events } \\
\hline & $\mathrm{N}$ & $\%$ & $\mathrm{~N}$ & $\%$ & $\mathrm{~N}$ & $\%$ & $\mathrm{~N}$ & $\%$ \\
\hline \multicolumn{9}{|l|}{ Age } \\
\hline $70-74$ (ref) & 2133 & 23.6 & 94 & 4.4 & 9775 & 38.7 & 286 & 2.9 \\
\hline $75-79$ vs. $70-74$ & 3218 & 35.6 & 162 & 5.0 & 7540 & 29.9 & 232 & 3.1 \\
\hline$\geq 80$ vs. $70-74$ & 3686 & 40.8 & 211 & 5.7 & 7930 & 31.4 & 264 & 3.3 \\
\hline \multicolumn{9}{|l|}{ BMI } \\
\hline Normal/underweight vs. overweight/obese & 2686 & 29.7 & 167 & 6.2 & 6699 & 26.5 & 295 & 4.4 \\
\hline \multicolumn{9}{|l|}{ Visit density ${ }^{\mathrm{b}}$} \\
\hline$<10$ (ref) & 672 & 7.4 & 26 & 3.9 & 7786 & 30.8 & 170 & 2.2 \\
\hline $10-19$ vs. $<10$ & 1379 & 15.3 & 46 & 3.3 & 7744 & 30.7 & 199 & 2.6 \\
\hline $20-29$ vs. $<10$ & 2753 & 30.5 & 123 & 4.5 & 6244 & 24.7 & 233 & 3.7 \\
\hline $30-39$ vs. $<10$ & 4233 & 46.8 & 272 & 6.4 & 3471 & 13.7 & 180 & 5.2 \\
\hline White vs. non-white ${ }^{c}$ & 5555 & 91.2 & 310 & 5.6 & 9050 & 91.8 & 332 & 3.7 \\
\hline \multicolumn{9}{|l|}{ Pre-existing conditions or exposures ${ }^{\mathrm{d}}$} \\
\hline Alcohol abuse-related disorder & 428 & 4.7 & 18 & 4.2 & 551 & 2.2 & 24 & 4.4 \\
\hline Blindness & 1235 & 13.7 & 60 & 4.9 & 1733 & 6.9 & 72 & 4.2 \\
\hline Cancer & 2960 & 32.8 & 210 & 7.1 & 5123 & 20.3 & 245 & 4.8 \\
\hline Deep vein thrombosis & 331 & 3.7 & 27 & 8.2 & 438 & 1.7 & 18 & 4.1 \\
\hline Depression & 1788 & 19.8 & 103 & 5.8 & 2899 & 11.5 & 132 & 4.6 \\
\hline Diabetes & 4903 & 54.3 & 268 & 5.5 & 11,793 & 46.7 & 378 & 3.2 \\
\hline Falls & 625 & 6.9 & 44 & 7.0 & 387 & 1.5 & 15 & 3.9 \\
\hline Fragility fracture & 180 & 2.0 & 13 & 7.2 & 106 & 0.4 & 11 & 10.4 \\
\hline Heart failure & 1872 & 20.7 & 96 & 5.1 & 2133 & 8.4 & 80 & 3.8 \\
\hline Hypertension & 7715 & 85.4 & 394 & 5.1 & 19,964 & 79.1 & 608 & 3.0 \\
\hline Malnutrition disorder & 860 & 9.5 & 58 & 6.7 & 682 & 2.7 & 41 & 6.0 \\
\hline Myocardial infarction & 1086 & 12.0 & 56 & 5.2 & 1633 & 6.5 & 59 & 3.6 \\
\hline Rheumatoid arthritis & 234 & 2.6 & 30 & 12.8 & 424 & 1.7 & 49 & 11.6 \\
\hline Seizures & 1066 & 11.8 & 54 & 5.1 & 1797 & 7.1 & 83 & 4.6 \\
\hline Smoking-related disorder & 950 & 10.5 & 49 & 5.2 & 1784 & 7.1 & 62 & 3.5 \\
\hline Stroke & 1555 & 17.2 & 71 & 4.6 & 2385 & 9.4 & 100 & 4.2 \\
\hline Thyroid disease & 1362 & 15.1 & 84 & 6.2 & 3439 & 13.6 & 136 & 4.0 \\
\hline \multicolumn{9}{|l|}{ Previous medication exposures ${ }^{\mathrm{d}}$} \\
\hline Antiandrogen & 1043 & 11.5 & 65 & 6.2 & 1837 & 7.3 & 68 & 3.7 \\
\hline Antidepressants & 2198 & 24.3 & 118 & 5.4 & 3846 & 15.2 & 177 & 4.6 \\
\hline Antiepileptic medications & 1066 & 11.8 & 54 & 5.1 & 1797 & 7.1 & 83 & 4.6 \\
\hline Finasteride & 538 & 6.0 & 28 & 5.2 & 880 & 3.5 & 29 & 3.3 \\
\hline Glucocorticoids & 1257 & 13.9 & 98 & 7.8 & 1326 & 5.3 & 95 & 7.2 \\
\hline GnRH analog & 223 & 2.5 & 32 & 14.3 & 259 & 1.0 & 34 & 13.1 \\
\hline H-2 receptor antagonists & 2718 & 30.1 & 133 & 4.9 & 4812 & 19.1 & 194 & 4.0 \\
\hline Heparin & 710 & 7.9 & 32 & 4.5 & 128 & 0.5 & 7 & 5.5 \\
\hline Loop diuretics & 2431 & 26.9 & 142 & 5.8 & 3644 & 14.4 & 112 & 3.1 \\
\hline Opioids & 4321 & 47.8 & 251 & 5.8 & 4734 & 18.8 & 195 & 4.1 \\
\hline Psychiatric medications & 1302 & 14.4 & 75 & 5.8 & 2110 & 8.4 & 95 & 4.5 \\
\hline Spironolactone & 448 & 5.0 & 20 & 4.5 & 875 & 3.5 & 25 & 2.9 \\
\hline Statins & 5132 & 56.8 & 253 & 4.9 & 14,099 & 55.8 & 410 & 2.9 \\
\hline Testosterone & 147 & 1.6 & 8 & 5.4 & 331 & 1.3 & 14 & 4.2 \\
\hline Thiazide diuretics & 3124 & 34.6 & 161 & 5.2 & 7421 & 29.4 & 211 & 2.8 \\
\hline
\end{tabular}

Key: BMI - body mass index; GnRH - Gonadotropin Releasing Hormone.

a Visit density is defined as the number of inpatient or outpatient encounters in the 1-year prior to the index date; it is a surrogate indicator of system familiarity with the patient

b \% based on patients with non-missing race data $(n=6091$ for primary care patients and 9864 for specialty care patients)

c Each comparison is for the presence of each characteristic vs. absence.

d Clinical identification of osteoporosis or fracture risk is defined as (1) a diagnosis of osteoporosis, (2) a prescribed treatment for osteoporosis including calcitonin, parathyroid hormone, or an osteoporosis bisphosphonate, or (3) an order for a bone mineral density test.

The strongest predictors of clinical identification for primary care patients were documented histories of gonadotropin releasing hormone $(\mathrm{GnRH})$ exposure (hazard ratio [HR] 2.8, $p<.0001$ ), fragility fractures (HR 2.4, $<.0001$ ) and diagnosis of rheumatoid arthritis (HR 2.0, $p=0.001)$. Clinicians were also more likely to identify osteoporosis or fracture risk in underweight or normal weight patients compared to patients who were overweight or obese and patients with histories of cancer, deep vein thrombosis, falls, malnutrition disorder, and patients with exposure to glucocorticoids, loop diuretics, and opioids. Clinicians were less likely to identify osteoporosis or fracture risk in patients with stroke. Interestingly, some clinical risk factors for fracture that were not associated with the composite outcome were smoking and alcohol abuse. The number of visits in the year prior to the index date (our surrogate for "system familiarity") also failed to predict the outcome with any accuracy.

\section{Clinical identification of osteoporosis or osteoporosis risk in specialty care patients}

In the multivariable model for specialty care models, BMI and system familiarity were significant predictors of clinical identification of osteoporosis but age and race were not. Similar to primary care patients, documented history of GnRH exposure (HR 4.1, $p<.0001$ ), fragility fractures (HR 3.0, $<<.0001$ ), and rheumatoid arthritis (HR 2.8, 
Table 2

Results of univariate and multivariable analyses for predictors of clinical identification of osteoporosis of fracture risk ${ }^{\mathrm{a}}$.

\begin{tabular}{|c|c|c|c|c|c|c|c|c|c|c|c|c|c|c|c|c|}
\hline \multirow[t]{3}{*}{ Characteristic } & \multicolumn{8}{|c|}{ Primary care visit (9037 patients; 102,541 observations) } & \multicolumn{8}{|c|}{ Specialty care visits only ( 25,245 patients; 278,175 observations) } \\
\hline & \multicolumn{4}{|c|}{ Unadjusted hazards for outcome ${ }^{\mathrm{a}}$} & \multicolumn{4}{|c|}{ Adjusted hazards for outcome ${ }^{a}$} & \multicolumn{4}{|c|}{ Unadjusted hazards for outcome $\mathrm{a}^{\mathrm{a}}$} & \multicolumn{4}{|c|}{ Adjusted hazards for outcome ${ }^{a}$} \\
\hline & $\mathrm{HR}$ & P value & \multicolumn{2}{|l|}{$95 \% \mathrm{CI}$} & $\mathrm{HR}^{\mathrm{b}}$ & P value & \multicolumn{2}{|l|}{$95 \% \mathrm{CI}$} & HR & P value & \multicolumn{2}{|l|}{$95 \% \mathrm{CI}$} & $\mathrm{HR}^{\mathrm{b}}$ & P value & \multicolumn{2}{|l|}{$95 \% \mathrm{CI}$} \\
\hline \multicolumn{17}{|l|}{ Age } \\
\hline 70-74 (ref) & - & - & - & - & - & - & - & - & - & - & - & - & - & - & - & - \\
\hline $75-79$ vs. $70-74$ & 1.167 & 0.233 & 0.906 & 1.504 & - & - & - & - & 1.060 & 0.508 & 0.892 & 1.261 & - & - & - & - \\
\hline$\geq 80$ vs. $70-74$ & 1.338 & 0.019 & 1.050 & 1.705 & - & - & - & - & 1.173 & 0.061 & 0.992 & 1.387 & - & - & - & - \\
\hline $\begin{array}{l}\text { BMI Normal/underweight vs. } \\
\text { overweight/obese }\end{array}$ & 1.356 & 0.002 & 1.122 & 1.638 & 1.290 & 0.012 & 1.057 & 1.573 & 1.720 & $<.0001$ & 1.489 & 1.988 & 1.625 & $<.0001$ & 1.401 & 1.886 \\
\hline \multicolumn{17}{|l|}{ Visit density ${ }^{\mathrm{C}}$} \\
\hline$<10$ (ref) & - & - & - & - & - & - & - & - & - & - & - & - & - & - & - & - \\
\hline $10-19$ vs. $<10$ & 0.835 & 0.464 & 0.515 & 1.353 & - & - & - & - & 1.153 & 0.174 & 0.939 & 1.415 & 1.046 & 0.670 & 0.851 & 1.285 \\
\hline $20-29$ vs. $<10$ & 1.147 & 0.524 & 0.752 & 1.750 & - & - & - & - & 1.688 & $<.0001$ & 1.385 & 2.057 & 1.236 & 0.043 & 1.007 & 1.519 \\
\hline $30-39$ vs. $<10$ & 1.657 & 0.014 & 1.108 & 2.476 & - & - & - & - & 2.324 & $<.0001$ & 1.885 & 2.867 & 1.297 & 0.028 & 1.028 & 1.637 \\
\hline White vs. non-white ${ }^{d}$ & 0.994 & 0.973 & 0.684 & 1.443 & - & - & - & - & 1.241 & 0.306 & 0.821 & 1.877 & - & - & - & - \\
\hline \multicolumn{17}{|l|}{ Pre-existing conditions $\mathrm{e}^{\mathrm{e}}$} \\
\hline Alcohol abuse-related disorder & 0.874 & 0.522 & 0.580 & 1.318 & - & - & - & - & 1.318 & 0.146 & 0.908 & 1.912 & - & - & - & - \\
\hline Blindness & 1.090 & 0.460 & 0.868 & 1.368 & - & - & - & - & 1.453 & 0.000 & 1.182 & 1.786 & 1.215 & 0.072 & 0.983 & 1.501 \\
\hline Cancer & 1.964 & $<.0001$ & 1.634 & 2.360 & 1.502 & $<.0001$ & 1.235 & 1.827 & 1.868 & $<.0001$ & 1.616 & 2.158 & 1.349 & 0.000 & 1.154 & 1.578 \\
\hline Deep vein thrombosis & 1.832 & 0.000 & 1.325 & 2.535 & 1.452 & 0.026 & 1.045 & 2.017 & 1.599 & 0.017 & 1.086 & 2.353 & - & - & - & - \\
\hline Depression & 1.284 & 0.015 & 1.051 & 1.570 & - & - & - & - & 1.592 & $<.0001$ & 1.343 & 1.888 & - & - & - & - \\
\hline Diabetes & 1.198 & 0.061 & 0.991 & 1.447 & - & - & - & - & 1.182 & 0.021 & 1.026 & 1.362 & - & - & - & - \\
\hline Falls & 2.461 & $<.0001$ & 1.984 & 3.052 & 1.658 & $<.0001$ & 1.310 & 2.098 & 2.026 & $<.0001$ & 1.472 & 2.788 & - & - & - & - \\
\hline Fragility fracture & 3.610 & $<.0001$ & 2.630 & 4.956 & 2.394 & $<.0001$ & 1.711 & 3.351 & 4.804 & $<.0001$ & 3.173 & 7.274 & 3.022 & $<.0001$ & 1.977 & 4.620 \\
\hline Heart failure & 1.184 & 0.098 & 0.970 & 1.446 & - & - & - & - & 1.373 & 0.002 & 1.125 & 1.677 & - & - & - & - \\
\hline Hypertension & 1.065 & 0.675 & 0.794 & 1.429 & - & - & - & - & 1.061 & 0.548 & 0.875 & 1.287 & - & - & - & - \\
\hline Malnutrition disorder & 1.941 & $<.0001$ & 1.569 & 2.401 & 1.426 & 0.002 & 1.141 & 1.782 & 2.283 & $<.0001$ & 1.794 & 2.905 & 1.254 & 0.084 & 0.970 & 1.621 \\
\hline Myocardial infarction & 0.967 & 0.791 & 0.751 & 1.244 & - & - & - & - & - & - & - & - & - & - & - & - \\
\hline Rheumatoid arthritis & 3.015 & $<.0001$ & 2.180 & 4.169 & 1.961 & $<.0001$ & 1.406 & 2.736 & 4.260 & $<.0001$ & 3.260 & 5.567 & 2.759 & $<.0001$ & 2.090 & 3.642 \\
\hline Seizures & 1.048 & 0.719 & 0.811 & 1.354 & - & - & - & - & 1.642 & $<.0001$ & 1.337 & 2.017 & 1.274 & 0.025 & 1.031 & 1.575 \\
\hline Smoking-related disorder & 1.035 & 0.809 & 0.785 & 1.364 & - & - & - & - & 1.249 & 0.062 & 0.989 & 1.578 & - & - & - & - \\
\hline Stroke & 0.892 & 0.332 & 0.709 & 1.123 & 0.786 & 0.041 & 0.623 & 0.990 & 1.337 & 0.003 & 1.102 & 1.623 & - & - & - & - \\
\hline Thyroid disease & 1.290 & 0.026 & 1.031 & 1.613 & 1.230 & 0.073 & 0.981 & 1.541 & 1.446 & $<.0001$ & 1.216 & 1.720 & 1.415 & $<.0001$ & 1.190 & 1.682 \\
\hline \multicolumn{17}{|l|}{ Previous medication exposures ${ }^{\mathrm{e}}$} \\
\hline Antiandrogen & 1.200 & 0.132 & 0.946 & 1.522 & - & - & - & - & 1.501 & $<.0001$ & 1.224 & 1.839 & & & & \\
\hline Antidepressants & 1.217 & 0.047 & 1.003 & 1.478 & - & - & - & - & 1.711 & $<.0001$ & 1.462 & 2.003 & 1.303 & 0.002 & 1.107 & 1.534 \\
\hline Antiepileptic medications & 1.048 & 0.719 & 0.811 & 1.354 & - & - & - & - & 1.642 & $<.0001$ & 1.337 & 2.017 & - & - & - & - \\
\hline Finasteride & 0.934 & 0.693 & 0.667 & 1.308 & - & - & - & - & 1.380 & 0.023 & 1.046 & 1.822 & - & - & - & - \\
\hline Glucocorticoids & 2.454 & $<.0001$ & 2.025 & 2.974 & 1.913 & $<.0001$ & 1.565 & 2.339 & 3.211 & $<.0001$ & 2.685 & 3.840 & 2.178 & $<.0001$ & 1.802 & 2.632 \\
\hline GnRH analog & 4.102 & $<.0001$ & 3.054 & 5.510 & 2.801 & $<.0001$ & 2.061 & 3.808 & 5.931 & $<.0001$ & 4.457 & 7.892 & 4.076 & $<.0001$ & 3.020 & 5.502 \\
\hline $\mathrm{H}-2$ receptor antagonists & 1.008 & 0.937 & 0.834 & 1.217 & 0.828 & 0.057 & 0.682 & 1.006 & 1.537 & $<.0001$ & 1.320 & 1.790 & 1.286 & 0.002 & 1.100 & 1.503 \\
\hline Heparin & 1.267 & 0.070 & 0.981 & 1.637 & - & - & - & - & 3.074 & $<.0001$ & 1.955 & 4.832 & - & - & - & - \\
\hline Loop diuretics & 1.506 & $<.0001$ & 1.250 & 1.814 & 1.220 & 0.043 & 1.007 & 1.479 & 1.202 & 0.038 & 1.010 & 1.430 & - & - & - & - \\
\hline Opioids & 1.754 & $<.0001$ & 1.438 & 2.139 & 1.288 & 0.018 & 1.044 & 1.589 & 1.854 & $<.0001$ & 1.603 & 2.145 & 1.254 & 0.006 & 1.068 & 1.472 \\
\hline Psychiatric medications & 1.272 & 0.031 & 1.022 & 1.582 & - & - & - & - & 1.516 & $<.0001$ & 1.245 & 1.848 & - & - & - & - \\
\hline Spironolactone & 1.000 & 1.000 & 0.696 & 1.437 & - & - & - & - & 1.042 & 0.811 & 0.744 & 1.458 & - & - & - & - \\
\hline Statins & 0.940 & 0.513 & 0.779 & 1.133 & - & - & - & - & 0.917 & 0.238 & 0.795 & 1.059 & - & - & - & - \\
\hline Testosterone & \multicolumn{4}{|c|}{$<10$ events } & \multicolumn{4}{|c|}{$<10$ events } & 2.030 & 0.001 & 1.359 & 3.030 & - & - & - & - \\
\hline Thiazide diuretics & 0.972 & 0.764 & 0.806 & 1.171 & - & - & - & - & 0.903 & 0.188 & 0.777 & 1.051 & - & - & - & - \\
\hline
\end{tabular}

Key: HR - hazards ratio; CI - confidence interval; BMD - bone mineral density; BMI - body mass index; GnRH - Gonadotropin Releasing Hormone.

a Clinical identification of osteoporosis or fracture risk is defined as (1) a diagnosis of osteoporosis, (2) a prescribed treatment for osteoporosis including calcitonin, parathyroid hormone, or an osteoporosis bisphosphonate, or (3) an order for a bone mineral density test.

b Adjusted for all other variables with estimates shown

c Visit density is defined as the number of inpatient or outpatient encounters in the 1-year prior to the index date; it is a surrogate indicator of system familiarity with the patient

d Based on patients with non-missing race data $(n=6091$ for primary care patients and 9864 for specialty care patients)

e Each comparison is for the presence of each characteristic vs. absence.

$p<.0001$ ) were strong predictors of clinical identification of osteoporosis. In addition, diagnoses of cancer, seizures, thyroid disease, and exposure to antidepressants, glucocorticoids, $\mathrm{H}-2$ receptor antagonists, and opioids were significantly associated with increased identification of osteoporosis in specialty care patients.

\section{Discussion}

We sought to identify patient and clinical characteristics that were associated with identification and treatment of osteoporosis in a cohort of male US veterans to better understand information constructs that might inform decision-making among clinicians. We did this using time-varying covariates to better model the clinical pathway and timing in which certain clinical or patient characteristics may lead the provider to diagnose, test for, or treat osteoporosis. We discovered that the strongest predictors of osteoporosis identification in both primary care and specialty care patients included exposure to GnRH analogs, fragility fractures, and diagnosis of rheumatoid arthritis. We also found differences in the risk factors that were significantly associated with identification of osteoporosis risk between patients with at least one primary care visit in the VA compared to those with only specialty care visits. For instance, deep vein thrombosis, fall history, stroke, and exposure to loop diuretics were all significant predictors of the outcome in primary care patients but not 
specialty care patients, whereas the opposite was true for seizures and exposure to antidepressants. Interestingly, some characteristics were strong clinical predictors of osteoporosis did not appear to be associated with the outcome of clinical identification in either primary care or specialty care patients, such as smoking- and alcoholrelated disorders. This suggests that clinicians are paying attention to some potential cues, but may be missing others.

Our findings do provide support for the conclusion that clinicians consider some risk factor constructs and important cues for osteoporosis risk. For example, we found that BMI was negatively associated with the outcome, consistent with previous literature [17], on which casefinding strategies recommended in current best practice guidelines are based [18]. Additionally, both prior fractures and falls, which are among the strongest predictors of future fractures [19-25], were strong predictors in our study. Similarly, exposure to oral glucocorticoids, which was significantly predictive of the outcome in both models, is also widely known to be associated with poor bone health and fracture [26-31].

Many of the significant risk factors identified in primary care patients were also present in the specialty care model. However, several inconsistencies in risk factors identified for primary care patients compared to specialty care patients highlight the differences in these two types of care. Risk factors significantly associated with clinical identification of osteoporosis for specialty care patients but not primary care patients were conditions that are familiar to specialists. For example, a psychiatrist would likely be aware of the association between selective serotonin reuptake inhibitor use and increased risk of fracture [32]. Similarly, the association between seizures and osteoporosis would be recognized by neurologists.

While many diagnoses and medications were associated with clinical identification of osteoporosis in both primary and specialty care patients, risk factors that are more behavioral in nature such as alcohol abuse and smoking status were not. Previous studies have found that clinicians spend less time discussing alcohol use with patients than other health-related behaviors [33]. Clinicians, therefore, may be missing opportunities to make the connections between alcohol abuse and its consequences. The poorly captured nature of smoking status in ICD-9 codes may explain the lack of significance in our models [34].

In terms of quality performance measures, the VHA generally exceeds those seen outside the VHA setting in numerous disease states, including human immunodeficiency virus [35], colorectal cancer [36], hyperlipidemia [37], and hypertension [38]. In fact, a recent study suggests that because of efforts to improve care in these other diseases that are much more common in males, the VHA have lagged behind other health systems in the diagnosis and treatment of osteoporosis [39]. We echo these authors' sentiments that this represents an opportunity for the VHA to improve the management of fractures and fracture risk among veterans.

\section{Limitations}

The major limitation in this analysis was that each patient's true underlying osteoporosis risk was not known. Our cohort consisted of all veterans who met inclusion criteria, including those with and without high fracture risk. Because our goal was to test which constructs were associated with identifying osteoporosis, it would have been ideal to have a cohort in which underlying osteoporosis risk was known to researchers (but unknown to clinicians at baseline) and to restrict the analysis to those patients who had high risk. However, we know of no such data for veterans. Nonetheless, because all our potential predictors have a known or theoretical association with fracture or bone quality, our results are robust to that issue. Patients with the exposures and characteristics of interest are, by definition, at a higher risk for fracture than those without. Other minor limitations include that we may have incomplete capture of outcomes, particularly those based on procedure and diagnosis codes.
While the low cost of prescriptions in the VHA provides an incentive for eligible veterans to obtain all of their prescriptions in the system, it is known that many veterans utilize outside systems for nonpharmaceutical care. If patients who obtain care from both VHA and non-VHA facilities are systematically different than those who use VHA exclusively, as several recent studies suggest [40-42], then this could bias the results in a variety of ways. We mitigated this limitation by restricting our analysis to veterans who had demonstrated a pattern of utilizing the VHA system for inpatient or outpatient care as well as identifying patients who had received at least one primary care visit prior to index. Additionally, patients with missing BMI values were excluded from our analysis. Patients with missing BMI differed significantly from patients with non-missing BMI on age, race, and number of visits. This suggests that BMI values were not missing at random in our study and that excluding them from our analysis may have introduced selection bias. A final limitation is that patients in this study were US veterans receiving care within one specific region of the VHA system (VISN 19) and may not be generalizable to veterans in other regions of the US.

\section{Future work}

The results of this study suggest that treatment and testing decisions can be better aligned with risk factors for osteoporosis fractures. Clinical reminders and other interventions designed to assist clinicians in identifying osteoporosis risk could improve osteoporosis prevention in the VHA.

\section{Conclusion}

In this study, we found that many patient characteristics identified in clinical and administrative datasets were associated with clinical identification of osteoporosis risk in a cohort of male US veterans age 70 and older. However, several other known risk factors were not associated with the outcome. Future work should focus on helping clinicians identify patients with high risk for fracture.

\section{Acknowledgments}

This work was sponsored by the Salt Lake City Veterans Affairs Geriatric, Research, Education, and Clinical Center (GRECC), the University of Utah Center on Aging Interdisciplinary Seed Grant, and by a grant from the Agency for Healthcare Research and Quality HS018582-01. We wish to thank Gregory J. Stoddard, Co-Director of University of Utah Study Design and Biostatistics Center, for reviewing our manuscript, providing suggestions, and confirming our statistical tools. We also wish to thank Kristin Knippenberg for her writing and editorial assistance.

\section{References}

[1] Looker AC, Orwoll ES, Johnston Jr CC, et al. Prevalence of low femoral bone density in older U.S. adults from NHANES III. J Bone Miner Res Nov 1997;12(11):1761-8.

[2] Burge R, Dawson-Hughes B, Solomon DH, Wong JB, King A, Tosteson A. Incidence and economic burden of osteoporosis-related fractures in the United States, 2005-2025. J Bone Miner Res Mar 2007;22(3):465-75.

[3] Official positions of the International Society for Clinical Densitrometry. West Hartdord, CT: International Society for Clinical Densitrometry; 2007.

[4] Clinician's guide to prevention and treatment of osteoporosis. Washington DC: National Osteoporosis Foundation; 2010.

[5] Morris CA, Cabral D, Cheng H, et al. Patterns of bone mineral density testing: current guidelines, testing rates, and interventions. J Gen Intern Med Jul 2004;19(7): 783-90.

[6] National Committee for Quality Assurance. Osteoporosis management in women who had a fracture: percentage of women 67 years of age and older who suffered a fracture, and who had either a bone mineral density (BMD) test or prescription for a drug to treat or prevent osteoporosis in the six months after the fracture. Washington, D.C: National Committee for Quality Assurance; 2007.

[7] Feldstein AC, Nichols G, Orwoll E, et al. The near absence of osteoporosis treatment in older men with fractures. Osteoporos Int Aug 2005;16(8):953-62. 
[8] Andrade SE, Majumdar SR, Chan KA, et al. Low frequency of treatment of osteoporosis among postmenopausal women following a fracture. Arch Intern Med 2003;163(17):2052-7.

[9] Kiebzak GM, Beinart GA, Perser K, Ambrose CG, Siff SJ, Heggeness MH. Undertreatment of osteoporosis in men with hip fracture. Arch Intern Med 2002;162(19):2217-22.

[10] Wehren LE, Hawkes WG, Orwig DL, Hebel JR, Zimmerman SI, Magaziner J. Gender differences in mortality after hip fracture: the role of infection. J Bone Miner Res Dec 2003;18(12):2231-7.

[11] Diamond TH, Thornley SW, Sekel R, Smerdely P. Hip fracture in elderly men: prognostic factors and outcomes. Med J Aust 1997;167(8):412-5.

[12] Vanasse A, Dagenais P, Niyonsenga T, Gregoire JP, Courteau J, Hemiari A. Bone mineral density measurement and osteoporosis treatment after a fragility fracture in older adults: regional variation and determinants of use in Quebec. BMC Musculoskelet Disord 2005;6:33.

[13] Nayak S, Roberts MS, Greenspan SL. Factors associated with diagnosis and treatment of osteoporosis in older adults. Osteoporos Int 2009;20:1963-7.

[14] Solomon DH, Katz JN, Jacobs JP, La Tourette AM, Coblyn J. Management of glucocorticoid-induced osteoporosis in patients with rheumatoid arthritis: rates and predictors of care in an academic rheumatology practice. Arthritis Rheum Dec 2002;46(12):3136-42.

[15] Nayak S, Roberts MS, Greenspan SL. Factors associated with osteoporosis screening and recommendations for osteoporosis screening in older adults. J Gen Intern Med May 2009;24(5):585-91.

[16] Steyerberg EW. Clinical prediction models: a practical approach to development, validation, and updating. New York: Springer; 2009.

[17] Siris ES, Miller PD, Barrett-Connor E, et al. Identification and fracture outcomes of undiagnosed low bone mineral density in postmenopausal women: results from the National Osteoporosis Risk Assessment. JAMA 2001;286(22):2815-22.

[18] Dawson-Hughes B. A revised clinician's guide to the prevention and treatment of osteoporosis. J Clin Endocrinol Metab 2008;93(7):2463-5.

[19] Black DM, Cummings SR, Karpf DB, et al. Randomised trial of effect of alendronate on risk of fracture in women with existing vertebral fractures. Fracture Intervention Trial Research Group. Lancet 1996;348(9041):1535-41.

[20] Black DM, Thompson DE. The effect of alendronate therapy on osteoporotic fracture in the vertebral fracture arm of the Fracture Intervention Trial. Int J Clin Pract Suppl Apr 1999;101:46-50.

[21] Cummings SR, Black DM, Thompson DE, et al. Effect of alendronate on risk of fracture in women with low bone density but without vertebral fractures: results from the Fracture Intervention Trial. JAMA Dec 23-30 1998;280(24):2077-82.

[22] Ettinger B, Black DM, Mitlak BH, et al. Reduction of vertebral fracture risk in postmenopausal women with osteoporosis treated with raloxifene: results from a 3year randomized clinical trial. Multiple Outcomes of Raloxifene Evaluation (MORE) Investigators. JAMA Aug 18 1999;282(7):637-45.

[23] Koike T, Orito Y, Toyoda H, et al. External hip protectors are effective for the elderly with higher-than-average risk factors for hip fractures. Osteoporos Int 2009 Sep;20(9):1613-20.

[24] Lindsay R, Silverman SL, Cooper C, et al. Risk of new vertebral fracture in the year following a fracture. JAMA 2001;285(3):320-3.
[25] Ross PD. Predicting bone loss and fracture risk with biochemical markers: a review. J Clin Densitom Fall 1999;2(3):285-94

[26] Adinoff AD, Hollister JR. Steroid-induced fractures and bone loss in patients with asthma. N Engl J Med 1983;309(5):265-8.

[27] Cooper C, Coupland C, Mitchell M. Rheumatoid arthritis, corticosteroid therapy and hip fracture. Ann Rheum Dis Jan 1995;54(1):49-52.

[28] Dykman TR, Gluck OS, Murphy WA, Hahn TJ, Hahn BH. Evaluation of factors associated with glucocorticoid-induced osteopenia in patients with rheumatic diseases. Arthritis Rheum Apr 1985;28(4):361-8.

[29] Hooyman JR, Melton III LJ, Nelson AM, O'Fallon WM, Riggs BL. Fractures after rheumatoid arthritis. A population-based study. Arthritis Rheum Dec 1984;27(12):1353-61.

[30] McDougall R, Sibley J, Haga M, Russell A. Outcome in patients with rheumatoid arthritis receiving prednisone compared to matched controls. J Rheumatol Jul 1994;21(7):1207-13.

[31] Saag KG, Koehnke R, Caldwell JR, et al. Low dose long-term corticosteroid therapy in rheumatoid arthritis: an analysis of serious adverse events. Am J Med Feb 1994;96(2):115-23.

[32] Richards JB, Papaioannou A, Adachi JD, et al. Effect of selective serotonin reuptake inhibitors on the risk of fracture. Arch Intern Med 2007;167(2):188-94.

[33] Arndt S, Schultz SK, Turvey C, Petersen A. Screening for alcoholism in the primary care setting: are we talking to the right people? J Fam Pract Jan 2002;51(1):41-6.

[34] Zeng QT, Goryachev S, Weiss S, Sordo M, Murphy SN, Lazarus R. Extracting principal diagnosis, co-morbidity and smoking status for asthma research: evaluation of a natural language processing system. BMC Med Inform Decis Mak 2006;6:30.

[35] Backus LI, Boothroyd DB, Phillips BR, et al. National quality forum performance measures for HIV/AIDS care: the Department of Veterans Affairs' experience. Arch Intern Med 2010;170(14):1239-46.

[36] Jackson GL, Melton LD, Abbott DH, et al. Quality of nonmetastatic colorectal cancer care in the Department of Veterans Affairs. J Clin Oncol 2010;28(19):3176-81.

[37] Cohen SM, Kataoka-Yahiro M. Provider adherence to clinical guidelines related to lipid-lowering medications. Mil Med Feb 2010;175(2):122-6.

[38] Choma NN, Huang RL, Dittus RS, Burnham KE, Roumie CL. Quality improvement initiatives improve hypertension care among veterans. Circ Cardiovasc Qual Outcomes Jul 2009;2(4):392-8.

[39] Shibli-Rahhal A, Vaughan-Sarrazin MS, Richardson K, Cram P. Testing and treatment for osteoporosis following hip fracture in an integrated U.S. healthcare delivery system. Osteoporos Int 2011 Dec;22(12):2973-80.

[40] Helmer D, Sambamoorthi U, Shen Y, et al. Opting out of an integrated healthcare system: dual-system use is associated with poorer glycemic control in veterans with diabetes. Prim Care Diabetes Jun 2008;2(2):73-80.

41] Carey K, Montez-Rath ME, Rosen AK, Christiansen CL, Loveland S, Ettner SL. Use of VA and Medicare services by dually eligible veterans with psychiatric problems. Health Serv Res Aug 2008;43(4):1164-83.

[42] Byrne MM, Kuebeler M, Pietz K, Petersen LA. Effect of using information from only one system for dually eligible health care users. Med Care Aug 2006;44(8): 768-73. 